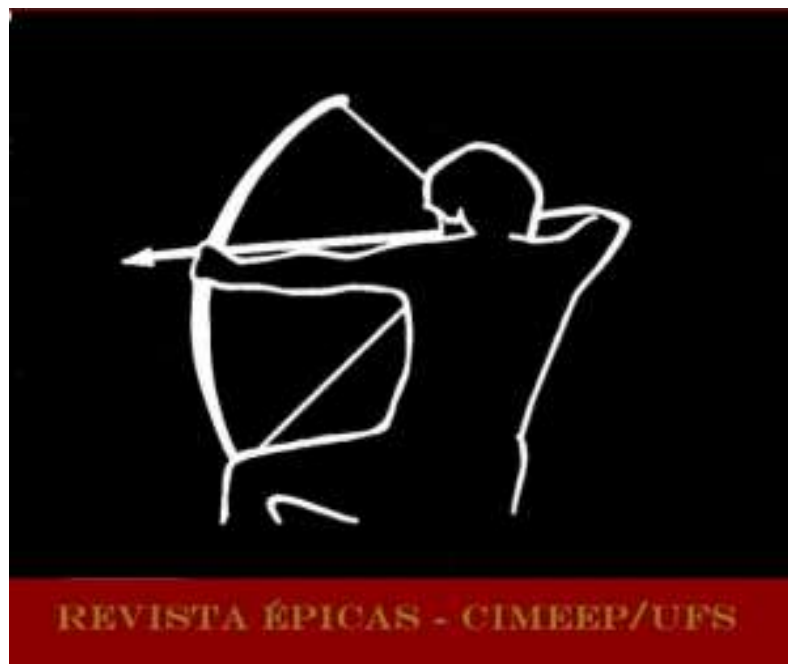

KIORIDIS, Ioannis. ¿Amigo o enemigo? Cristianos y musulmanes en el romancero español y las baladas tradicionales griegas. In: Revista Épicas. Ano 5, N. 9, Jun 2021, p. 114-122. ISSN 2527-080-X. DOI: http://dx.doi.org/10.47044/2527-080X.2021v9114122

\title{
¿AMIGO O ENEMIGO? CRISTIANOS Y MUSULMANES EN EL ROMANCERO ESPAÑOL Y LAS BALADAS TRADICIONALES GRIEGAS*
}

\section{AMIGO OU INIMIGO? CRISTÃOS E MUÇULMANOS NO ROMANCEIRO ESPANHOL E NAS BALADAS TRADICIONAIS GREGAS}

loannis Kioridis ${ }^{1}$

Hellenic Open University

RESUMEN: El artículo bajo consideración constituye una aproximación comparativa entre el romancero español y las baladas tradicionales griegas. Lo que se pretende concretamente es estudiar la relación entre los cristianos y los musulmanes en los romances épicos y fronterizos y sus análogos griegos, los cantos acríticos. Mediante fragmentos de ambos géneros se presenta la relación de amistad o de enemistad, de convivencia o de odio entre cristianos y musulmanes. Se estudian aspectos como la guerra, la alianza entre pueblos y los descendientes de ambas razas. El trabajo llega a su fin con unas consideraciones finales.

Palabras claves: Romancero español, baladas tradicionales griegas, romances épicos y fronterizos, cantos acríticos, estudio comparativo

RESUMO: $\mathrm{O}$ artigo em análise constitui uma abordagem comparativa entre os romanceiros espanhóis e as tradicionais baladas gregas. O que se pretende concretamente é estudar a relação entre cristãos e muçulmanos nos romances épicos e de fronteira e seus análogos gregos, os cantos acríticos. Através de fragmentos de ambos os gêneros, apresenta-se a relação de amizade ou inimizade, convivência ou ódio entre cristãos e muçulmanos. São estudados aspectos como a guerra, a aliança entre os povos e os descendentes de ambas as raças. O trabalho é encerrado com algumas considerações finais.

Palavras-chave: Romanceiros espanhol, baladas gregas tradicionais, romances épicos e fronteiriços, canções acríticas, estudo comparativo

\footnotetext{
* El presente estudio forma parte de las actividades desarrolladas en el marco del Proyecto Científico PGC2018095757-B-I00: MEHHRLYN_02 (MCIU/AEI/FEDER, UE.

${ }^{1}$ Miembro del GT 6 del CIMEEP. ORCID: https://orcid.org/0000-0002-6577-1004.
} 


\section{Introducción}

Tanto Grecia como España, ya desde las épocas del imperio bizantino y los reinos visigodos, fueron invadidas por diversos pueblos que, ansiando ampliar sus imperios, tenían como primer objetivo a estos dos países. Así, la larga estancia de los invasores musulmanes en estas tierras conllevó, más allá del carácter meramente militar, un mestizaje de culturas que, a la larga, contribuiría a enriquecer a ambos países. Varias facetas de la vida se vieron enriquecidas por la presencia del invasor musulmán.

Estas relaciones, en las que se mezclaba la amistad con el odio, se vieron reflejadas en la literatura, especialmente los textos épicos, los textos cronísticos y las baladas, fuesen estas romances fronterizos o cantos acríticos. Estos últimos serán nuestro objeto de estudio, a fin de comprobar los testimonios sobre la convivencia o coexistencia, así como la veracidad o ficción de los mismos.

Los romances son la expresión de las baladas en España. Se trata de canciones narrativas formadas por un número indeterminado de versos, normalmente octosílabos con rima asonante en los versos pares, quedando sin rima los impares. Esto se debe a que, según la teoría más aceptada, su origen provendría de cantares de gesta, cuyos versos de 16 sílabas tenían una cesura por la que se dividieron los versos de los romances. También existen variantes, como romances hexasílabos (cuyos poemas originales serían de doce sílabas). A partir de la forma original surgieron luego otros poemas que adoptaban esa forma y, a la larga, incluían importantes variaciones que se separaban mucho de los romances primeros, como en el caso de algunos romances tardíos del siglo XVIII que incluyen rima consonante (DÍAZ MAS, 2006, p. 7-25).

Por otra parte, las baladas tradicionales griegas forman el comienzo de la literatura neogriega (siglo X). Son principalmente de carácter oral y de verso político, es decir, de 15 sílabas y estructura bimembre, con una estructura interna de dos hemistiquios de 8 y 7 sílabas en cada verso, que es regular con respecto al número de sílabas y a la distribución de los acentos principales (CASTILLO DIDIER, 1994, p. 67-68).

De los varios tipos de estas canciones populares, nosotros estudiaremos las más primitivas, que son narrativas y se llaman acríticas. Las raíces de esta poesía debieron coincidir con la creación en el siglo VIII del cuerpo de los Akritai, los guardianes de la frontera bizantina, y que perduraron hasta su disolución en el siglo XIII. Después, las canciones dejaron de crearse y solo se difundían oralmente las ya compuestas.

Estas creaciones y la épica bizantina narran las hazañas de los Akritai contra los sarracenos y los apelates -una especie de bandidos-. Asia Menor y, sobre todo, Capadocia, Pontos y toda la zona fronteriza entre bizantinos y árabes fueron la cuna de estas obras. Con el 
paso del tiempo las canciones acríticas a menudo se apartaron de su espítiru inicial -la lucha contra los musulmanes- $y$ adoptaron otros motivos como el matrimonio o la muerte, entre otros.

\section{La guerra}

El contexto por el que moros y cristianos entraron en contacto fue el de una invasión. Es por ello lógico que buena parte de los textos donde las dos culturas aparecen estén asociados con la guerra. Se trata de la mayoría de textos, de los cuales hay aquí algunos ejemplos, empezando por testimonios bizantinos:

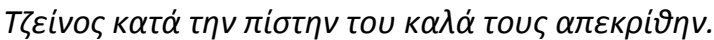

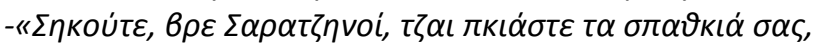
$\mu \varepsilon \mu \pi \varepsilon i \tau \varepsilon \dot{\varepsilon} \delta \omega \kappa \alpha \pi \dot{\alpha} v \omega \sigma \alpha \varsigma \alpha \dot{\alpha} \rho \alpha \alpha \zeta \alpha \iota \dot{\alpha} \rho \pi \alpha \xi \dot{\alpha} \sigma \alpha \varsigma »$.

[Arestis les saludó de acuerdo con su fe:

- «Levantaos, sarracenos, y empuñad vuestras espadas, y no digáis que os ataqué sin que antes no os avisara».] (La canción de Armuris, vv. 91-93)

(AYENSA, 2004, p. 156-157)

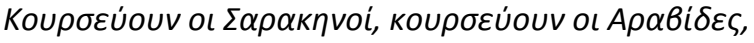

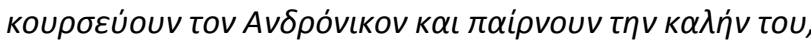
$\varepsilon \gamma \gamma \alpha \tau \sigma \rho \omega \mu \varepsilon \dot{v} v^{\prime} \varepsilon v v l \alpha \dot{\alpha} \mu \eta v \dot{v} v, \tau \eta \varsigma \omega^{\prime} \rho \alpha \varsigma$ v $\alpha \varepsilon v v \eta \dot{\sigma} \sigma \varepsilon l$.

[Algaras de sarracenos, algaras también de árabes, saquean la casa de Andrónico y raptan a su esposa, embarazada de nueve meses y a punto de parir.] (El hijo de Andrónico, vv. 1-3)

(AYENSA, 2004, p. 166-167)

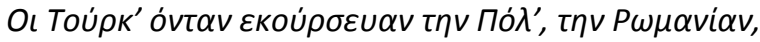

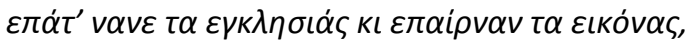

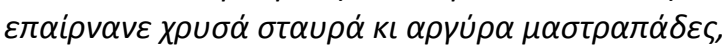

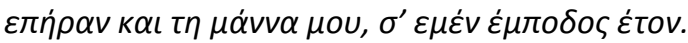

[Cuando los turcos saquearon Constantinopla, la Romania, hollaron las iglesias y se llevaron los iconos, se llevaron todas las cruces y los cálices de plata y se llevaron a mi madre, que de mí estaba preñada.] (EI hijo de Andrónico, versión de Trebisonda, Ponto, vv. 1-4) (AYENSA, 2004, p. 174-175)

El siguiente fragmento pertenece al romancero español, también sobre la misma temática:

Los cristianos eran muchos - mas llevaban orden mala; los moros, que son de guerra, - dádoles han mala carga: d' ellos matan, d' ellos prenden, - d' ellos toman en celada. 
Con la victoria los moros - van la vuelta de Granada;

a grandes voces decían: - - iLa victoria ya es cobrada!

(Pérdida de Antequera, vv. 21-25)

(DÍAZ MAS, 2006, p. 172)

En cierto modo, es comprensible que la guerra entre moros y cristianos sea un tema recurrente en las canciones acríticas y los romances, sean estos fronterizos o no, ya que las teorías más aceptadas establecen que tanto el origen de los romances como el de las canciones acríticas se hallaría en las composiciones épicas españolas y bizantinas. Sin embargo, como se verá, estos textos de carácter bélico servirán para plantear la posibilidad de que, en realidad, la convivencia era lo normal, y no la guerra.

\title{
Las alianzas entre pueblos
}

No sólo la guerra figura en estas obras. De hecho, las literaturas bizantina y castellana recogen diversos casos de convivencia de moros y cristianos en un mismo suelo. Un ejemplo que ratifica esta idea figura, de nuevo, en los cantos de frontera griegos: en uno de ellos, Jandinós pierde a su hijo Vasilis y se lanza en pos de su búsqueda:

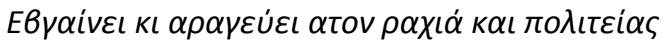

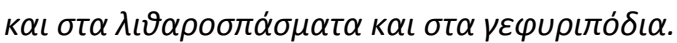

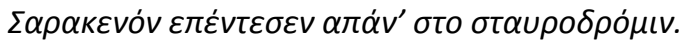

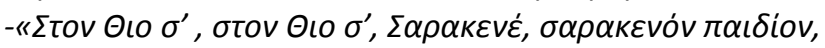

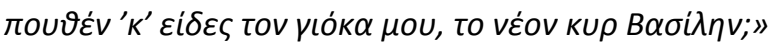 \\ [Por ciudades lo buscó, por puentes y por canteras, \\ y a un sarraceno encontró en un cruce de caminos: \\ -«Por amor de Dios, sarraceno, por Dios, joven sarraceno, \\ ¿viste tú en algún lugar a mi pobre hijo Vasilis? »»] \\ (Jandinós, versión de Trebisonda, Ponto, vv. 7-11) \\ (AYENSA, 2004, p. 62-63)
}

El joven sarraceno, por supuesto, posee esa información y la transmite a Jandinós: su hijo está prisionero, y trabaja en la reconstrucción de un castillo. No sólo le dice dónde encontrará a Vasilis, sino que incluso le dice cómo puede salvar a su hijo.

Esta colaboración entre ambos personajes, a nuestro parecer, sí que constituye un reflejo de la relativa convivencia existente entre musulmanes y cristianos. No puede dejarse de lado el respeto que ambos parecen profesarse, el amable saludo de Jandinós, y la respuesta sin reparos del sarraceno. Existe una cierta colaboración, como Jandinós podría haberle preguntado a un vecino suyo. El que este personaje musulmán aparezca en el texto no debía de parecer extraño a quienes lo oían, ni tampoco que Jandinós no le sacase la información tras derrotarle en combate. 
Sin embargo, algunos de los ejemplos más comunes sobre la convivencia entre moros y cristianos quedan patentes en los textos donde aparecen alianzas entre miembros de ambas culturas. Así sucede con las bodas por las que estos pueblos se alían:

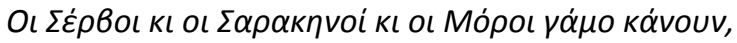

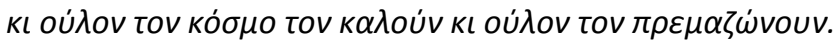

[Serbios, moros y sarracenos celebraron una boda. A todo el mundo invitaron, a todo el mundo reunieron, (Diyenís no es invitado a una boda, versión de Creta, vv. 1-2) (AYENSA, 2004, p. 82-83)

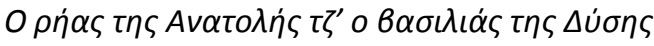

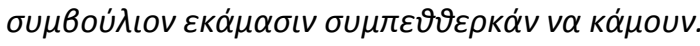

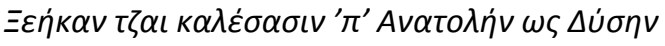

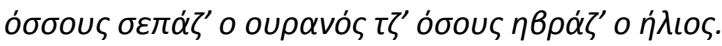

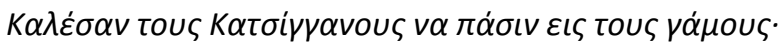

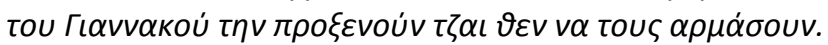

[El monarca de Oriente y el rey de Occidente un trato cerraron para casar a sus hijos. A todos invitaron, de Oriente a Occidente, a cuantos cubre el cielo, a cuantos abrasa el sol, y para mediar en la boda invitaron a unos gitanos, para casar a la princesa y unirla con Yannacós.] (Diyenís y la hija del rey Levandis, versión de Chipre, vv. 1-6) (AYENSA, 2004, p. 68-69)

No son unas bodas por amor, sino unas bodas concertadas por los dos reyes para conseguir la aliaza de sus pueblos. Se trata de algo real, pues no sólo los reyes, sino las familias nobles casaban a sus miembros entre sí para aliarse y aumentar su poder al unirse. No hay que escandalizarse cuando, por un lado, era algo normal y todavía lo ha sido hasta hace poco entre las grandes casas nobles europeas. Además, como se verá, cuando el amor aparece en las baladas no tiene porqué representar el noble sentimiento.

En el caso de España, contamos con un excelente testimonio sobre alianzas que no se basan en bodas, sino en otra bien distinta:

Por el val de las Estacas pasó el Cid a mediodía en su caballo Babieca, oh, qué bien que parecía. El rey moro que lo supo a recibirle salía; dijo: -Bien vengas, el Cid; buena sea tu venida, que si quieres ganar sueldo muy bueno te lo daría o si vienes por mujer darte he una hermana mía. -Que no quiero vuestro sueldo ni de nadie lo querría; que ni vengo por mujer que viva tengo la mía. Vengo a que pagues las parias que tú debes a Castilla. -No te las daré yo, el buen Cid; Cid, yo no te las daría; si mi padre las pagó hizo lo que no debía. 


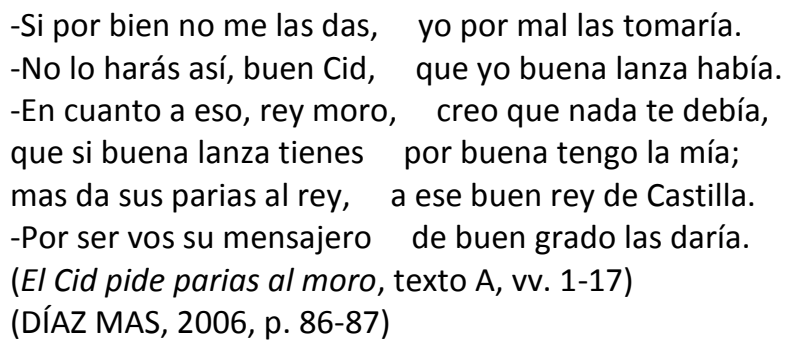

Lo que describe este romance es una realidad nacida, precisamente, en tiempos del Cid Campeador (siglo XI). El final del califato de Córdoba llevó a la fragmentación de su territorio en reinos de taifas, cuyos soberanos podían luchar entre sí para conquistar sus reinos y así extender sus territorios. Estos nuevos reinos eran débiles, y aún más al combatirse mutuamente, lo cual hizo que algunos reyes se aliasen con los cristianos pagándoles las parias, impuestos que los reyes islámicos pagaban a los cristianos. A cambio de ese pago, los cristianos les prestaban su ayuda y protección contra otros enemigos, fuesen éstos moros o cristianos. La fe no era lo único que contaba, sino también la política.

De hecho, lo que muestra este romance -la relación amistosa por conveniencia políticaqueda ratificado por otros testimonios literarios, como sucede con el caso de Abengalvón, el moro amigo del Cid en el Cantar de Mio Cid. Se trata de un "amigo de paz", lo cual implica que mantiene una relación amistosa y le sirve por ser uno de esos señores musulmanes que pagaban parias a los cristianos -en este caso, al Cid mismo-. Como se observa, esa paz se puede romper si la alianza no es respetada, como sucede cuando el rey moro decide no pagar los tributos. Afortunadamente, el Cid convence con una amenaza al rey para que pague. Estas relaciones políticas implican, por tanto, una convivencia más o menos amistosa, pero también por interés. ${ }^{2}$

\section{Los descendientes de ambas razas}

La convivencia de moros y cristianos aparece también reflejada en personajes que son descendientes de ambas razas. Tienen todos ellos unos rasgos comunes:

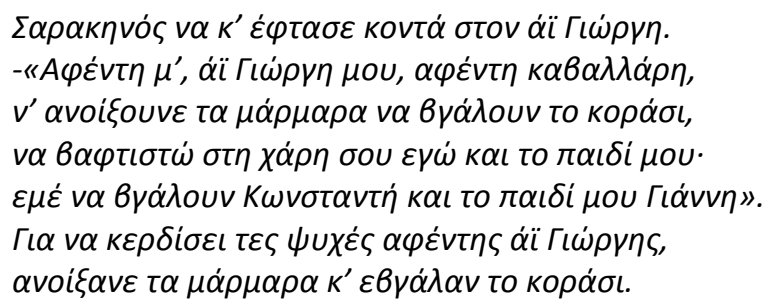

[Y el sarraceno también llegó a la iglesia de San Jorge.

- «Señor mío, San Jorge, señor mío, caballero,

\footnotetext{
2 Para más información sobre estos temas en el $C M C$, véanse la edición magnífica de Montaner, 2016. Para los que

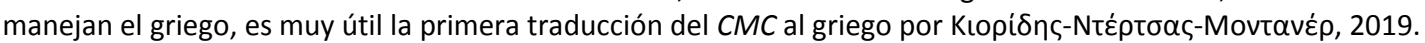


si tus mármoles se abren y aparece la doncella, por ti nos bautizaremos tanto yo como mi hijo Costandís será mi nombre y el de mi hijo será Juan». Para ganar sus dos almas el caballero San Jorge sus mármoles abrió y apareció la doncella.]

(La doncella valiente, versión de la isla de Léucade, vv. 17-23) (AYENSA, 2004, p. 56-57)

Aquí aparece un mensaje típico en las épicas bizantina, española y francesa: en realidad, no se refleja totalmente una convivencia, en cuanto que el personaje moro acaba siempre convirtiéndose al cristianismo. Aquí, por ejemplo, el sarraceno promete a San Jorge que tanto él como su hijo se harán cristianos. Este mensaje, que sirve para mostrar la importancia de la religión en estas culturas, quizá no tanto en lo que a la fe se refiere sino como elemento común a todos los miembros de una cultura, se observa incluso en el caso de algunos héroes nacidos de la unión carnal entre moros y cristianos:

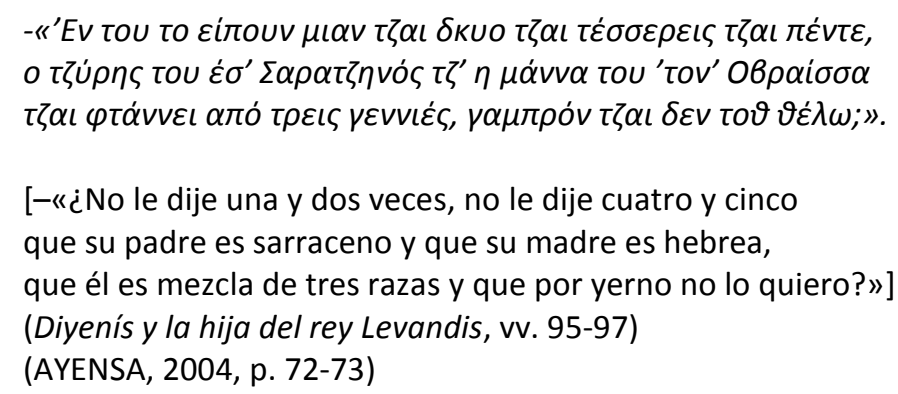

En cierto modo, Digenís, el héroe principal de la épica bizantina y las canciones acríticas, representa la unión de distintas razas, y esto podría simbolizar la coexistencia de las mismas. Sin embargo, precisamente su suegra le rechaza por ser un mestizo; no sólo eso: en el canto épico dedicado al héroe, su padre, el Emir, se convierte al cristianismo para así poder casarse con Irene, futura madre Digenis, que es también cristiana. Por tanto, no se refleja esa tolerancia, ese respeto, sino al contrario, estos testimonios muestran el deseo de que las razas no se mezclen: podían coexistir, incluso convivir, pero dentro de ciertos límites, pues no se buscaba que se mezclasen. Por ello, el que Digenís sea una mezcla de razas -al igual que otro héroe español, Mudarra, hijo de una mora y un cautivo cristiano- no implica, a nivel literario, que hubiese paz entre estos pueblos.

El rey Almanzor cuidoso - consigo se lo llevaba [a Gonzalo Gustos] y mandó a una morica - lo sirviese muy de gana; ésta le torna en prisiones - y con amor le curaba; hermana era del rey, - doncella moza y lozana.

Con ésta Gonzalo Gustos - vino a perder su saña, que d' ella le nació un hijo - que a los hermanos vengara. 
(Llanto de Gonzalo Gustioz, vv. 51-56)

(DÍAZ MAS, 2006, p. 54)

-Si a ti te dicen don Rodrigo - y aun don Rodrigo de Lara, a mí Mudarra González, - hijo de la renegada, de Gonzalo Gustos hijo - y anado de doña Sancha;

(Venganza de Mudarra, vv. 14-16)

(DÍAZ MAS, 2006, p. 56)

Sin embargo, en España existe un caso interesante donde no se habla de conversión del moro al cristianismo:

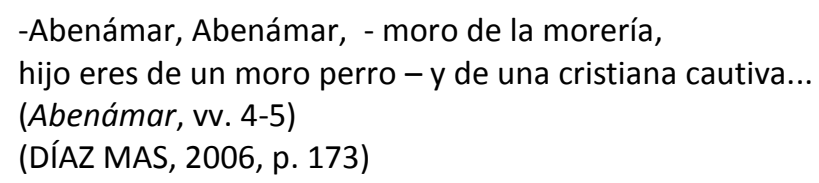

Sin embargo, hay que tener en cuenta que, en el poema, Abenámar es un moro que colabora con los cristianos en la toma de Granada. Su ayuda queda justificada por su sangre cristiana, heredada de su madre. Por tanto, aunque su padre no fuese cristiano, él está claramente orgulloso de su origen materno y por ello ayuda a los cristianos.

\section{Interpretación de estos textos}

Las referencias a estas situaciones pacíficas entre moros y cristianos son pocas en comparación con las referencias a situaciones de conflicto, entre estos pueblos. El propio romance de "El Cid pide parias al moro" indica que la paz era muy frágil, y que las alianzas podían romperse, por lo que la guerra podía estallar en cualquier momento. No es necesario, a nuestro parecer, comentar aquí el argumento de cada uno de los textos que remiten a las situaciones de guerra, pues esto sería más propio de un estudio introductorio a una edición antológica más que de un artículo. Sin embargo, la gran presencia de textos referidos a pasajes violentos de la historia de Grecia y España permite pensar sobre la naturaleza de estos textos, así como de su tratamiento de las relaciones entre moros y cristianos.

Sin embargo, creemos que el mayor número de romances y baladas griegas dedicados a la guerra puede que implique, en realidad, la excepcionalidad de la misma, mientras que esos pequeños, casi insignificantes, pasajes referidos a la paz y la convivencia podrían indicar, en realidad, que ésta era la situación habitual. La idea sobre lo que se asienta esto es muy sencilla: por un lado, si los romances y las canciones acríticas nacen de los cantos épicos, es lógico que se refieran a la guerra. Por otro lado, lo habitual, lo rutinario, no impresiona por no ser excepcional, de ahí que nadie les dedique ningún canto, ninguna novela. Por contra, sí es posible 
que lo habitual figure como escenario, como contexto dentro del cual surge lo excepcional, lo que rompe esa relativa armonía existente en la vida cotidiana.

Aquí queda claro, por tanto, el valor de los pequeños pasajes referidos a la coexistencia pacífica entre moros y cristianos no sólo por su existencia, sino por su baja presencia que, tanto en el caso bizantino como el español, indican que la situación real, habitual, era la de una cierta estabilidad pacífica. La mayor cantidad de textos, tanto en Grecia como España, dedicados a la guerra, van dedicados a los momentos más importantes, o incluso excepcionales, de los conflictos existentes entre ambas culturas. Pero el que no se dé importancia a una boda entre miembros de distintas razas, o que un cristiano pueda hablar con un moro para preguntarle dónde está su hijo, debía de ser algo tan habitual como el cobro de parias que aparece en el romance del Cid y el moro donde, de hecho, no se está cantando al cobro en sí mismo, sino al hecho de que el rey moro se opusiese a pagar, y cómo el Cid salva la situación para que todo vuelva a la normalidad.

\section{Referencias bibliográficas}

AYENSA PRAT, Eusebi (Texto y trad.). Cancionero griego de frontera en la serie Nueva Roma. vol. 23, Madrid: CSIC, 2004.

CASTILLO DIDIER, Miguel. Poesía heroica griega: Epopeya de Diyenís Akritas, Cantares de Armuris y de Andrónico. Santiago: Universidad de Chile, 1994.

DÍAZ MAS, Paloma (ed.). Romancero. Barcelona: Crítica, 2006.

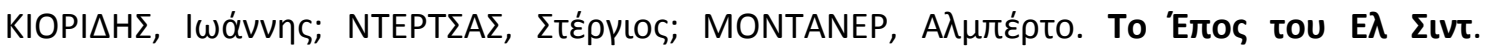

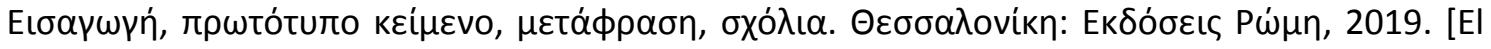
Cantar de mio Cid. Introducción, texto original, traducción, notas].

MONTANER, Alberto. El Cantar de mio Cid. edición, estudio y notas. 2.a ed. rev. Madrid: Real Academia Española - Barcelona: Galaxia Gutenberg-Círculo de Lectores, 2016. 